\title{
THE AUSTRIAN EOSC MANDATED ORGANISATION / THE EOSC SUPPORT OFFICE AUSTRIA
}

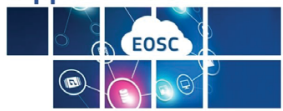

by Susanne Blumesberger, Florian Brandt, Paolo Budroni, Juliana De Mello Castro Giroletti, Andreas Ferus, Katharina Flicker, Raman Ganguly, Beate Guba, Stefan Hanslik, Ilire Hasani-Mavriqi, Lisa Hönegger, Tereza Kalová, Michael Kranewitter, Bernd Logar, Christian Panigl, Heimo Rainer, Andreas Rauber, Barbara Sánchez Solís, Bernd Saurugger, Chris Schubert, Katrin Vohland, Kerstin Zimmermann*

Abstract: This report offers some reflections for a better understanding of the realization of the European Open Science Cloud (EOSC) at a local level, describing the implementation of the newly established Austrian EOSC Mandated Organisation and the EOSC Support Office Austria.

Keywords: EOSC; Austrian EOSC Initiative; research data; data infrastructure; data stewardship

\section{DIE ÖSTERREICHISCHE EOSC MANDATED ORGANISATION / DAS EOSC SUPPORT OFFICE AUSTRIA}

Zusammenfassung: Dieser Bericht bietet einige Überlegungen zum besseren Verständnis der Umsetzung der European Open Science Cloud (EOSC) auf nationaler Ebene und schildert die Entstehung der neu gegründeten österreichischen EOSC Mandated Organisation und des EOSC Support Office Austria.

Schlagworte: EOSC; Österreichische EOSC-Initiative; Forschungsdaten; Dateninfrastruktur; Data Stewardship

DOI: https://doi.org/10.31263/voebm.v74i2.6270

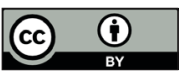

This work - excl. individual logos and illustrations - is licensed under a Creative Commons Attribution 4.0 International license 
The European Open Science Cloud (EOSC) envisions establishing a European data infrastructure, integrating high-capacity cloud solutions, eventually widening the scope of these services to include the public sector and industry. In November 2018 the European Commission launched the European Open Science Cloud (EOSC) at the University of Vienna. Two years later the EOSC Association was established as a legal entity on $29^{\text {th }}$ July 2020 with four founding members. In January 2021 TU Wien created a new organizational unit, the EOSC and International Liaison Office, based at TU Wien Bibliothek - and in February 2021 the ACONET Association applied for membership in the EOSC Association as Austrian Mandated Organisation.

In the meantime, four Austrian RIs applied to become a Member of the EOSC Association AISBL: The Natural History Museum Vienna (NHM), TU Graz, TU Wien and University of Vienna (UNIVIE). The status of an "Observer" was requested by the Climate Change Centre Austria (CCCA) and the Johannes Kepler University of Linz (JKU). The Academy of Fine Arts Vienna will follow in short.

These are the direct Austrian players. The main questions related to the development of EOSC in Austria are: what does it mean to implement the EOSC at a domestic level, and how does it fit with the newly launched EOSC Association? How can Austrian communities engage with EOSC? How can Austrian EOSC Stakeholders contribute to the structuring of these co-creation processes? How can the communities addressed help to prepare the transition to a new "Stakeholder-based governance" at a domestic level?

This report offers some reflections for a better understanding of the realization of EOSC at a local level at the present stage, including the newly established Austrian EOSC Mandated Organisation and the EOSC Support Office Austria.

\section{Preliminaries}

In Austria the operative EOSC-related activities are led by the Austrian Federal Ministry of Education, Science and Research (BMBWF) that has assigned an EOSC Steering Board member. As the operation and further development of the Austrian NREN "ACOnet" is strategically supported and controlled by an association ("ACONET Verein"), the BMBWF has asked this association to act as a neutral bridging body, to assume a mandated role, and to apply as a representative of Austria in the EOSC Association AISBL. 
In order to be able to fulfill this task, the ACONET association needs an executive body with an appropriate staff capacity, and TU Wien offered default liability through a contract. TU Wien offered to take over this role based on its extensive involvement in the EOSC building process and through its activities in the EOSC Secretariat Project (Leader of Sub Task "Researcher Engagement"). TU Wien also offered a physical infrastructure for the Austrian initiative, which is now acting as a contact point for the EOSC Association AISBL and has been named the EOSC Support Office Austria/EOSC Mandated Organisation. ${ }^{2}$ It is important to emphasize the neutral status of the EOSC Support Office Austria, which is meant to represent the convergence of interest of all involved Austrian Stakeholders. The development of the EOSC Support Office Austria is further supported by the regional H2020 project EOSC-Pillar with the University of Vienna as main partner. Within the project EOSC-Pillar, UNIVIE has the lead in activities such as the monitoring of the RI landscape and stakeholder engagement - activities that will be aligned with the Austrian EOSC initiative and will benefit the establishment and operation of the EOSC Support Office Austria.

\section{Kick-off}

On $26^{\text {th }}$ March, 2021, after some preliminary talks and with the participation of BMBWF, the ACONET Association, the Austrian EOSC Members and Observers, further national initiatives, such as the RDA-Austrian National Node and the FAIR Office Austria, organized a kick-off meeting. The meeting was useful in learning about stakeholder sentiments and in defining the objectives until June 2021. The main decision taken during the meeting was to organize meetings on a regular basis ("weekly meetings") until July 2021, aiming at obtaining these outcomes:

- to define the spirit of the initiative,

- to define the minimum requirements needed to run the joint office,

- to create a virtual environment for the EOSC Support Office Austria,

- to create a setting for the coordination of activities,

- to create a trusted virtual space_at domestic level (National Wiki), with Terms of Use,

- to create Austrian EOSC Points of Reference based at each participating institution or related initiative,

- to define a good governance model compliant with EOSC and the EOSC Association,

- to define the related rules of participation, 
- to create a rotation model in the Management of the EOSC Mandated Organisation/EOSC Support Office Austria,

- to define Working Groups mirroring the activities of the Task Forces of the EOSC Association, and finally,

- to translate the governance model into a written consensual agreement (MoU),

- to organize a Validation Workshop in July 2021 - with the aim of codifying the then obtained common results and

- to prepare the General Assembly of partners of the Austrian EOSC initiative, to be held in October 2021.

The development of the Consensual agreement (MoU) of the "Austrian EOSC Mandated Organisation/EOSC Support Office Austria" included defining the following:

- the relationship of the partners to each other,

- the regulation of operations,

- the institutions and the management including the rights, duties and responsibilities with respect to the initiative, and

- the results including free access to the joint work carried out within the initiative and relevant information with respect to the assignment of intellectual property rights.

\section{The Austrian EOSC Initiative: Moment of truth as per October 2021 - Organization and structure}

Following the decisions taken at its first General Assembly ${ }^{3}\left(13^{\text {th }}\right.$ October, 2021 ) the internal management structure of the partner community consists of the following bodies:

a) The General Assembly acts as the representative body and as the final body responsible for decision-making.

b) The Management ensures the optimization of processes and acts as an intermediary and coordinator between the institutions of the Community and the partners.

c) The Steering Committee sets the basic orientation of the project.

d) The Synergy Team bears the responsibility for expertise in each discipline. Several Working Groups act in the frame regulated by the Synergy Team.

e) The Reflection Group ("Austrian EOSC Café - Open Forum") provides external influence and stimulus. 
A trusted virtual space at domestic level was installed as a platform for communication. A centralised web-based Wiki, available to all partners, provides the organisational framework for the pooling of resources, the centralization and brokerage of current information about the project status, meetings, documentation as well as stimulating the exchange of experiences and knowledge. This Wiki is regulated by clearly defined terms and conditions of use, with a binding commitment to Open Access.

All above mentioned bodies are inherent to the daily operations of the EOSC Mandated Organisation/EOSC Support Office Austria, with one exception, the Reflection Group.

The Reflection Group is a team of experts of multidisciplinary organisations (such as industry, public administration, the Austrian national funding body for science and research) that provides insight and expertise to the different organisational units of the initiative Austrian Mandated Organisation. The Reflection Group actively participates in the definition of long-term development strategies and provides motivation for their implementation. The Reflection Group promotes networking and exchange with similar Austrian and European institutions working in similar projects, and ensures that Austria is connected to the rest of the world in research matters. Moreover, it promotes access to decision-makers in Austria and in the European Union, and facilitates access to qualified and structured data and information.

The Coordinator of the Reflection Group is the Austrian Representative at the EOSC Steering Board.

The Management of the initiative is responsible for the operational activities and ensures the quality of the initiative's actions. The management consists of a Management Board and a Secretariat. Four representatives for the Management Board have been elected among the partners, with only one representative per partner to ensure the balance of power and interests as well as to strengthen the neutral status of the EOSC Support Office Austria, which represents the convergence of interests of all Austrian stakeholders involved.

The operations of the Management will be supported by the future team of the EOSC Support Office, whose main activities are: Providing support to the Management Board concerning coordination of the initiative, coordination of back-office functions, establishing and maintaining a contact network with opinion leaders within the partner institutions participating in the initiative, supporting the experts in the individual Work Packages, monitoring and analysis of developments in each Work Package of the project, actively participating in meetings and events, organising partner events, and supporting marketing activities in cooperation with the Management and partners. 


\section{Focus of Activities}

The following eight fields of action were identified, and they are interlinked:

- Stakeholder Engagement

- Enlargement of Membership

- Landscaping Activities

- Key Performance Indicators (measurement of success, adoption of EOSC KPIs)

- Engagement of Providers

- Engagement of Users

- Increase of Awareness (e.g. through training activities)

- Reflection on Sustainable Business Models

\section{Working Groups}

Following the identification of the fields of action, it has been decided to propose some Working Groups (WGs), mirroring, where possible, the supranational level (EOSC Association AISBL). At this stage, the WGs may be divided into two clusters: WGs that have started operations, and WGs that are on the way to be settled/that are on the way to be designed.

a) Working Groups that have started activities:

\section{Austria Country Report}

The task of this WG is to regularly monitor EOSC building processes in Austria, i.e. open science and FAIR related policies, projects, activities as well as RDM infrastructures. Its report will be updated on a quarterly basis. First deadline was $23^{\text {rd }}$ June, 2021. The second report was published at the end of Quarter II. ${ }^{4}$

Coordination WG Austria Country Report: Barbara Sánchez Solís (TU Wien)

\section{Key Performance Indicators (KPIs)}

The WG on Key Performance Indicators (KPIs) develops measurable indicators to make the success of EOSC visible at international/European level along the overarching goals for Austria ("readiness indicators"), at the level of the EOSC Support Office AT, as well as at institutional level. In 
addition, KPIs are a steering instrument for targeted impact-oriented further development and EOSC-compliant implementation and stakeholder readiness.

The WG also develops and adapts suitable methods; they may be percentages of FAIR data, surveys, or social network analyses.

The KPIs have been discussed in a first workshop with external experts and stakeholders on $18^{\text {th }}$ October, 2021. The focus of the workshop was to determine their feasibility and significance, to coordinate with the EOSC-AT WGs (especially the WG Austria Country Report) as well as to align with and give feedback to international EOSC initiatives.

The KPI WG sees itself as responsible for the content and conceptual design.

Coordination WG Key Performance Indicators: Katrin Vohland (NHM), Beate Guba (TU Wien)

\section{Researcher Engagement in Austria}

The EOSC should meet the requirements and needs of daily research in Austria. At the same time, EOSC services should be widely accepted within the Austrian research landscape. Activities of this WG - of which all are to be well documented and/or published in the form of e.g. reports, papers, or recommendations - support achieving this objective.

Since the WG Researcher Engagement in Austria has been established in 2019 in the context of the EOSC Secretariat initiative as supporting activity of the EOSC building process, the WG can build on already existing networks, extensive experiences and numerous publications. ${ }^{5}$ At the next meeting of this WG - scheduled for late November/early December 2021 - activities and the distribution of work will be defined.

Coordination WG Researcher Engagement in Austria: Katharina Flicker (TU Wien)

\section{Data Stewardship}

Data stewards are experts in the field of research data management and bring their expertise to the organization. Their role is being newly established at Austrian research institutions. In addition, the development and definition of a data steward profile as well as training offers and career paths for data stewards are an essential part of the EOSC Association Advisory Group - "Research careers and curricula". The aim of this working group is 
to coordinate developments at national level, especially in connection with the FAIR Data Austria project, and to contribute to the "TF Data stewardship curricula and career paths". Activities include workshops with national research institutions, reports, position papers, recommendations and exchanges with international communities.

\section{Coordination WG Data Stewardship: Ilire Hasani-Mavriqi (TU Graz)}

\section{Technical Infrastructure}

The activities of this working group are based on preliminary work and results of related projects (e.g. FAIR Data Austria, Austrian DataLAB and Services, EuroCC, EuroCC Austria, IDE@S). Activities include working with the community to coordinate the implementation and rollout of FAIR tools and services, as well as to provide interactive access to HPC clusters and accessible data science tools and resources. The results of the EOSC Association Task Forces such as "Technical Interoperability of Data and Services", "AAI", "Infrastructure for quality research software" and "Longterm preservation" will be considered to create an overarching and integrating outlook.

\section{Coordination WG Technical Infrastructure: Claire Jean-Quartier (TU Graz)}

\section{Training}

The working group aims to make existing training materials more accessible and visible as Open Educational Resources, but also to develop new training materials where needed and to fill gaps in the range of training courses currently offered. The training materials should be in line with the FAIR principles. They should be easy to find, accessible, both adapted to specific circumstances, but also generic and thus interchangeable, and available long term. The working group is therefore committed to reviewing existing materials, adding appropriate metadata and making them more widely available. As there is already a wide range of training resources in English, the working group will focus particularly on materials in German, either by developing new training or by translating high-quality content from other languages. Since many Austrian research institutions already offer training on data management, the goal is to collect and document these materials and make them available on one platform. The WG will work together with other initiatives to select an established RDM 
training platform that will raise the international visibility of the materials from Austrian research institutions.

Existing training materials should not only be made available via a permanent link but also provided with contextual information. The content of the training, the target group and the possibilities of use will thus become more transparent. The description should include information such as language, accessibility, keywords, target group and as such simplify the search and (re)use for training materials.

Coordination WG Training: Susanne Blumesberger (University of Vienna)

b) Working Groups that are on the way to be settled/that are on the way to be designed:

\section{Stakeholder Engagement}

EOSC activities in Austria need to address as many stakeholders as possible. For example, information on and knowledge exchange with European initiatives such as EuroHPC, EuroCC 6 and GAIA-X, or digitalization projects on the Austrian level (e.g. FAIR Data Austria, Austrian Data Lab and Serves and RIS Synergy) are crucial for the EOSC Support Office Austria to work efficiently. This WG thus focuses on facilitating such a flow of information without creating extra demands for resources (e.g. by making use of communication channels that already are in place). The approach is twofold: First, relevant stakeholders will be identified and mapped as a baseline for further engagement activities. Second, actual engagement activities are to be derived from this baseline. The objective is to identify best practices of engagement and sustain the knowledge exchange between networks.

Coordination WG Stakeholder Engagement: Raman Ganguly (University of Vienna)

\section{Collections}

Collections represent a special research infrastructure whose digital assets (inventories, 2D and 3D figures, voices) are the basis for research, development, creativity and communication. Moreover, collections are located in the area of the third mission of the universities. The diverse collections, ranging from natural and geoscientific collections to works of art and born digital collections, thrive on the linkage with other data, be it 
geographical, biographical, historical or climatic. Their use requires comprehensive availability and interoperability. Therefore, on the one hand, this WG will work very closely with the FAIR Office Austria as well as with the other working groups, especially the WG Training, and address the national collection landscape of museums and universities. On the other hand, it will be inherently active internationally in order to introduce developments at the global level into the Austrian research infrastructure initiatives. This includes all aspects necessary for cross-domain interoperability: Adoption and active co-design of standards, workflows, and data pipelines.

Coordination WG Collections: Heimo Rainer (NHM)

\section{Major challenges and how to deal with them}

Such a complex initiative, developed within a tight timeframe, encompassing a wide range of entities operating in scientific fields, requires management that is attentive and skillful in responding to stakeholder requirements.

In addition, and for better implementation of the initiative, it was determined that from the outset that the initiative would adopt guidelines, reflecting the orientation indicated by EOSC and principles set by the open science movement.

\section{The Guiding Principles of the Austrian EOSC Initiative}

The major challenges are derived from the ambitious Guiding Principles, which are enumerated in the Memorandum of Understanding (MoU), and they summarize the spirit of the Austrian EOSC Initiative. They are defined as follows:

a) Openness: open communication between all partners in the partner network.

b) Culture of Dialogue: Encouraging a "culture of dialogue" to promote institutional networking and exchange of ideas.

c) Access: The partners are committed to free access to the results of the joint operation in the project.

d) Ownership of rights: The project partners ensure the sustainability of the results by a defined ownership of rights within and outside the network. 
e) Recognizable roles: regulated relationship between all project partners by means of defined organizational units and processes. Roles and responsibilities are clearly visible from the inside and outside.

f) Structured approach: The operation of the working groups/work packages is defined by controlled sessions, responsibilities, well defined voting, and communication.

g) Clear information infrastructure: The project partners have at their disposal a common, nation-wide information infrastructure established in the form of a Wiki.

\section{Corporate behavior}

Another challenge arises from an area that can be defined as "EOSC Austria corporate behavior".

Heterogeneity characterizes the Austrian research landscape. The different stakeholders active in the Austrian EOSC Initiative are also members and observers of the EOSC Association AISBL and experience to a certain extent forms of competition among them. To this already fragmented landscape entities are added which are not members of the EOSC Association, but which are important for the European Open Science Cloud or for the Open Science movement. The identification of this challenge means that from the outset the measures taken must pay more attention to what can be described as team spirit building, while at the same time attention must be paid to a careful balance of power.

Community building is closely linked to corporate behaviour, and the management of the initiative devoted particular interest and effort to achieving a high level of satisfaction in the different working groups, observing the different wishes expressed in the course of the work, and above all involving all parties in managing a memorandum of understanding that reflects the priorities defined by the partners.

\section{Good governance models and balance of power}

A major challenge in the setup of the initiatives' structure and the definition of the good governance of the initiative is the balance of power among the participating partners, especially in light of the above-mentioned different roles in the Austrian research and RIs landscape, in the EOSC Association and in the wider EOSC community. The Austrian Initiative addressed this challenge through a detailed structure of committees with clear com- 
petencies, voting and election processes as well as a rotation principle in leadership and in representation of the initiative.

\section{Open Science, a challenge and an opportunity. The relationship to the Austrian Open Science Policy}

According to Directive (EU) 2019/1024 of $20^{\text {th }}$ June, 2019 on open data and the re-use of public sector information ("Open Data and Public Sector Information Directive"), ${ }^{7}$ the EU member states have to adopt national strategies and to support relevant measures with the aim of making publicly funded research data openly accessible according to the principle of "open data by default" and in accordance with the FAIR principles. Together with the objectives of the EU in the field of research and data policy, a recommendation by OANA (Open Science Network Austria, a joint initiative of the national funder Austrian Science Fund - FWF and Universities Austria - uniko) for an Open Science strategy formed the basis for the development of an Austrian policy (in the sense of a common orientation) on open science and the European Open Science Cloud (EOSC).

Austria actively supports the development of an open, transparent and inclusive science and promotes the FAIR handling of research processes and their results. With a clear commitment to "Horizon Europe" and Austria's active participation in the European Research Area (ERA), Open Science was included in the federal government's strategy for research, technology and innovation (FTI Strategie 2030).

As a result, intensive work was carried out on the development of an Austrian policy on open science and the European Open Science Cloud. Three Austrian Ministries were involved in this development process at the working level, under the direction of the Austrian Federal Ministry for Education, Science and Research (BMBWF). In the course of this, the relevance of participation in the process of implementing the European Open Science Cloud (EOSC), as World Wide Web of FAIR data and services, was expressly pointed out. The Open Science Policy was prepared in quarter IV/2021 as a final draft and brought forward for further consideration at ministerial level.

The Austrian EOSC initiative: Open Science by default. The partners in the Austrian initiative decided from the outset and by mutual agreement that the initiative would be developed in an 'Open Science by default' mode. This spirit is evident in the text of the Memorandum of Understanding (Consensual Agreement), which has been validated on 
$12^{\text {th }}$ July, 2021 and prepared for signature not only by the Austrian Members and Observers, but also by any other entity or EOSC-related initiative that wishes to make a concrete contribution to the development of the Austrian initiative. ${ }^{8}$

\section{Implementation of the Austrian Mandated Organisation}

\section{a) Mirroring the EOSC Association AISBL}

The "Austrian EOSC Mandated Organisation" and the "EOSC Support Office Austria" are created within the framework of the formation of the European Open Science Cloud (EOSC) and the EOSC Association AISBL. The partners are united by their common interest in the coordinated development of requirements and implementations in accordance with the Austrian open science and EOSC goals.

The aim of the "EOSC Support Office Austria" is to establish a real "Austrian EOSC Mandated Organisation", the function of which is currently legally performed by the ACONET Association.

\section{b) The Weekly Meetings}

After the kick-off meeting it was decided that all partners involved should meet once a week. These meetings were coordinated by the TU Wien and took place until the "Validation Workshop" (12 ${ }^{\text {th }}$ July, 2021). Also, the modality of rotating the coordination was practiced: this was then taken over by the partners TU Graz, University of Vienna, The Natural History Museum Vienna - NHM and then again handed over to TU Wien.

\section{c) The Validation Workshop}

A Validation Workshop was held in $12^{\text {th }}$ July, 2021. The following topics were jointly decided, validated and defined as the basis for further joint action by all partners involved after prior discussion: The Guiding Principles of the initiative, The contents of the Consensual Agreement (MoU), The acting bodies of the joint initiative, especially the Management, the Working Groups, the common wiki, the work plan (at the time of the validation workshop), the definition of the resources needed for operations, the date of the official kíck-off of the joint initiative (official establishment of the bodies of the initiative).$^{9}$ 


\section{d) Embedding existing EOSC related initiatives and their current results into the Austrian Mandated Organisation}

In the development of the preparatory activities, as many existing initiatives and projects as possible were considered from the beginning, and the representatives of these activities were invited to the meetings. Among them are: the Horizon 2020 projects EOSC Secretariat (TU Wien) and EOSC-Pillar (University of Vienna), Research Data Alliance Austria National Node, the Austrian national delegates of the e-Infrastructures Reflection Group and the recently founded FAIR Office Austria.

\section{e) Liaison with EOSC Nodes in Europe}

Another activity that was consistently carried out was to establish contacts with similar initiatives in Europe (EOSC Nodes) and the holding of virtual meetings with colleagues from the Italian Initiative and the Swedish Initiative. Inquiries were also made to colleagues in Croatia, Switzerland, and Hungary. In June, the Austrian initiative was presented together with others at the EOSC Symposium.

\section{f) The "Austrian EOSC - Strategic Innovation Agenda"}

Perhaps the most important activity planned for this fall, besides the kick-off meeting, would be the editing of the Austrian EOSC Innovation Agenda. This should become a living document, which will be subject to constant updates. The preparation of the work will take place after the General Assembly.

\section{Unique selling propositions of the Austrian Mandated Organisation}

The Austrian initiative has a few outstanding features that have characterized it from the outset and which have already been mentioned and presented above. These are:

- The initiative is developed in an 'open science by default' mode.

- The initiative has been continuously managed from the beginning by a dedicated reflection group that includes as many players as possible and whose cooperation started in 2017 - in the time before the EOSC launch.

- Communication will take place via a trusted virtual platform (Austrian National EOSC Wiki), with terms of use that underline the Open Science character of the initiative. 
- The management of the initiative is based on a rotation principle, which is intended to guarantee the balance of power in the partner network and compliance with the guiding principles.

- Existing EOSC related initiatives and their current results are embedded from the beginning into the Austrian Mandated Organisation.

On ZENODO, the community "EOSC Austria" was created to serve all Austrian stakeholders as a common platform for published documents: https://zenodo.org/ communities/eosc-austria/

Mag. ${ }^{a}$ Dr. ${ }^{\text {in }}$ Susanne Blumesberger, MSc ORCID iD: https://orcid.org/0000-0001-9018-623X University of Vienna, Library and Archives E-Mail: susanne.blumesberger@univie.ac.at

Florian Brandt, MSc Austrian Federal Ministry for Education, Science and Research (BMBWF) E-Mail: florian.brandt@bmbwf.gv.at

Dr. Paolo Budroni ORCID iD: https://orcid.org/0000-0001-7490-5716 TU Wien, EOSC and International Liaison Office E-Mail: paolo.budroni@tuwien.ac.at

Juliana De Mello Castro Giroletti, MSc ORCID iD: https://orcid.org/0000-0002-1111-2548 TU Wien, EOSC and International Liaison Office E-Mail: juliana.giroletti@tuwien.ac.at

Mag. Andreas Ferus, MSc ORCID iD: https://orcid.org/0000-0003-2509-0009 Academy of Fine Arts Vienna, Library E-Mail: a.ferus@akbild.ac.at

Katharina Flicker, B.A. M.A. ORCID iD: https://orcid.org/0000-0001-6040-2798 TU Wien, Institute of Information Systems Engineering E-Mail: katharina.flicker@tuwien.ac.at 
Dipl.-Ing. (FH) Raman Ganguly ORCID iD: https://orcid.org/0000-0002-9837-0047 University of Vienna, Vienna University Computer Center E-Mail: raman.ganguly@univie.ac.at

Mag. ${ }^{a}$ Beate Guba, MSc ORCID iD: https://orcid.org/0000-0002-1106-0805 TU Wien, Library E-Mail: beate.guba@tuwien.ac.at

Dr. Stefan Hanslik Austrian Federal Ministry for Education, Science and Research (BMBWF) E-Mail: stefan.hanslik@bmbwf.gv.at

Dipl.-Ing. ${ }^{\text {in }}{ }^{\text {Dr. }}{ }^{\text {in }}$ Ilire Hasani-Mavriqi ORCID iD: https://orcid.org/0000-0003-0758-0805 Graz University of Technology, Institute of Interactive Systems and Data Science E-Mail: ilire.hasani-mavriqi@tugraz.at

Lisa Hönegger, BA BA MA ORCID iD: https://orcid.org/0000-0001-6530-7343 University of Vienna, AUSSDA - The Austrian Social Science Data Archive E-Mail: lisa.hoenegger@univie.ac.at

Tereza Kalová, MA (Res), M.A. LIS ORCID iD: https://orcid.org/0000-0002-1764-7228 University of Vienna, Library and Archives E-Mail: tereza.kalova@univie.ac.at

Mag. Michael Kranewitter ORCID iD: https://orcid.org/0000-0003-3436-6011 Johannes Kepler University Linz, Library E-Mail: michael.kranewitter@jku.at

Dipl.-Ing. Bernd Logar TU Wien, Information Technology Solutions E-Mail: bernd.logar@tuwien.ac.at 
Christian Panigl

ORCID iD: https://orcid.org/0000-0002-0957-556X University of Vienna, ACOnet \& Vienna Internet eXchange E-Mail: christian.panigl@univie.ac.at

Mag. Heimo Rainer ORCID iD: https://orcid.org/0000-0002-5963-349X Natural History Museum Vienna E-Mail: heimo.rainer@nhm-wien.ac.at

Ao.Univ.Prof. Dipl.-Ing. Dr. techn. Andreas Rauber ORCID iD: https://orcid.org/0000-0002-9272-6225 TU Wien, Institute of Information Systems Engineering E-Mail: andreas.rauber@tuwien.ac.at

Mag. ${ }^{a}$ Barbara Sánchez Solis ORCID iD: https://orcid.org/0000-0002-3574-2755 TU Wien, Center for Research Data Management E-Mail: barbara.sanchez@tuwien.ac.at

Bernd Saurugger, BSc ORCID iD: https://orcid.org/0000-0001-5730-3983 TU Wien, Institute of Information Systems Engineering E-Mail: bernd.saurugger@tuwien.ac.at

Dipl.-Geol. Chris Schubert ORCID iD: https://orcid.org/0000-0002-4971-2493 TU Wien, Library E-Mail: chris.schubert@tuwien.ac.at

Dr. ${ }^{\text {in }}$ Katrin Vohland ORCID iD: https://orcid.org/0000-0002-7214-7015 Natural History Museum Vienna E-Mail: katrin.vohland@nhm-wien.ac.at

Dipl.-Phys. ${ }^{\text {in }}$ Kerstin Zimmermann Austrian Federal Ministry for Climate Action, Environment, Energy, Mobility, Innovation, and Technology (BMK) E-Mail: kerstin.zimmermann@bmk.gv.at 
Annex 1: General Assembly, elected members

\begin{tabular}{|c|c|}
\hline First Chair of the General Assembly & Paolo Budroni, TU Wien \\
\hline Second Chair of the General Assembly & Maria SeissI, UNIVIE \\
\hline Members of the Steering Committee & $\begin{array}{l}\text { Josef Eberhardsteiner, TU Wien; } \\
\text { Claudia von der Linden, } \\
\text { TU Graz; Christopher Lindinger, } \\
\text { JKU; Ronald Maier, UNIVIE; } \\
\text { Chris Schubert (representing ad } \\
\text { interim CCCA); Katrin Vohland, } \\
\text { NHM }\end{array}$ \\
\hline $\begin{array}{l}\text { Coordinator of the Steering Committee } \\
\text { Deputy Coordinator of Steering Committee }\end{array}$ & $\begin{array}{l}\text { Katrin Vohland, NHM } \\
\text { Claudia von der Linden, } \\
\text { TU Graz }\end{array}$ \\
\hline Members of the Management Board & $\begin{array}{l}\text { Ilire Hasani-Mavriqi, TU Graz; } \\
\text { Heimo Rainer, NHM; Tereza } \\
\text { Kalová, UNIVIE; Gerhard } \\
\text { Wotawa, CCCA }\end{array}$ \\
\hline $\begin{array}{l}\text { First Chair of the Management Board } \\
\text { (Coordinator) }\end{array}$ & $\begin{array}{l}\text { TU Graz, represented by llire } \\
\text { Hasani-Mavriqi }\end{array}$ \\
\hline Second Chair of the Management Board & NHM, repr. by Heimo Rainer \\
\hline Third Chair of the Management Board & UNIVIE, repr. by Tereza Kalová \\
\hline Fourth Chair of the Management Board & $\begin{array}{l}\text { CCCA, represented by ZAMG, } \\
\text { Gerhard Wotawa }\end{array}$ \\
\hline Coordinator of the EOSC Café & Stefan Hanslik, BMBWF \\
\hline Spokespersons of the Synergy Team & $\begin{array}{l}\text { Barbara Sánchez Solís, } \\
\text { TU Wien; Susanne } \\
\text { Blumesberger, UNIVIE; } \\
\text { Claire Jean-Quartier, TU Graz }\end{array}$ \\
\hline
\end{tabular}

Mitteilungen der VÖB 74 (2021) Nr. 2: Digitale und soziale Transformation 
Annex 2: The Entities involved in the Austrian EOSC Initiative (as of October 2021)

- ACONET Association [legal entity of the Austrian Mandated Organisation]

- Academy of Fine Arts Vienna [official Candidate Observer at EOSC Association AISBL]

- Climate Change Centre Austria [Observer of EOSC Association AISBL]

- Johannes Kepler University Linz [official candidate Observer at EOSC Association AISBL]

- Natural History Museum Vienna [Member of EOSC Association AISBL]

- Graz University of Technology [Member of EOSC Association AISBL]

- Vienna University of Technology [Member of EOSC Association AISBL]

- University of Vienna [Member of EOSC Association AISBL]

\section{Extraordinary Partners of the EOSC Austria Initiative}

- Federal Ministry of Education, Science and Research (BMBWF)

- ACOnet (NREN)

- FAIR Office Austria

Annex 3. Contributors and Participants to the EOSC Mandated Organisation/EOSC Support Office Austria (named alphabetically) - as of October 2021

Susanne Blumesberger, Florian Brandt, Paolo Budroni, Juliana De Mello Castro Giroletti, Josef Eberhardsteiner, Katharina Flicker, Johannes Fröhlich, Raman Ganguly, Eva Gergely, Alexander Gruber, Beate Guba, Stefan Hanslik, Ilire Hasani-Mavriqi, Lisa Hönegger, Claire Jean-Quartier, Tereza Kalová, Sabrina Knopper, Michael Kranewitter, Bernd Logar, Claudia von der Linden, Christopher Lindinger, Ronald Maier, Christian Panigl, Heimo Rainer, Andreas Rauber, Barbara Sánchez Solís, Bernd Saurugger, Chris Schubert, Katrin Vohland, Kerstin Zimmermann 
* Contributors are named alphabetically; corresponding author: Paolo Budroni, Chair of GA of Partners.

1 NREN: National Research and Education Network.

2 The address of the office is: EOSC Support Office Austria, TU Wien, Favoritenstraße 16/5th floor, 1040 Vienna, Austria.

3 The records and the takeaways of the first General Assembly (GA) have been published on Zenodo and are available at https://doi. org/10.5281/zenodo.5588259. The composition of the bodies of the GA is illustrated in Annex 1.

4 The WG Austria Country Report has published the "Austrian Country Profile" in Zenodo in October 2021. Link: https://doi.org/10.5281/zenodo. 5571922

5 For reports on researcher engagement activities, see https:/doi. org/10.5281/zenodo.4626957, https://doi.org/10.5281/zenodo.4336705, https://doi.org/10.5281/zenodo.4015121, https://doi. org/10.5281/zenodo.3701194 and https://doi.org/10.5281/zenodo.3693914. Key takeaway messages can be downloaded at https:// doi.org/10.5281/zenodo.4627019, https://doi.org/10.5281/zenodo.4337176, https://doi.org/10.5281/zenodo.4030301 and https:// doi.org/10.5281/zenodo.3701269. Apart from this, recommendations for researcher engagement (https://doi.org/10.5281/zenodo.4784822), and a collection of initiatives and services to support cutting-edge research (https://doi.org/10.5281/zenodo.5596597) were published.

6 The European High Performance Computing Joint Undertaking (EuroHPC JU) is a joint initiative between the EU, European countries and private partners to develop a World Class Supercomputing Ecosystem in Europe. EuroCC (European Competence Centre) is an international project to support research and innovation in High-Performance Computing (HPC) in Europe.

7 A first workshop on Open Data and the Public Sector Information Directive was held on $20^{\text {th }}$ October, 2021: Shaping EOSC - Open Data and the European Data Strategy. Ein Workshop zur Etablierung der PSI-Richtlinie (Public Sector Information Directive) und der Bildung der European Open Science Cloud in Österreich, Martin Semberger, Federal Ministry Republic of Austria, Digital and Economic Affairs; Paolo Budroni, EOSC and International Liaison Office at TU Wien Bibliothek.

8 The terms of the Consensual Agreement laid the basis for the implementation of the first General Assembly (13 $3^{\text {th }}$ October, 2021). The Consensual Agreement will be signed in November 2021 by all Partners.

9 As mentioned, the first General Assembly was then held on $13^{\text {th }}$ October, 2021. 